\title{
ECAME: A Software for the Evaluation of the Quality of Estuarine and Marine Waters for the Preservation of Flora and Fauna
}

\author{
Iris Jiménez-Pitre', Jordi Rafael Palacio Gonzalez² and Geomar Molina-Bolívar ${ }^{1 *}$ \\ 'BIEMARC, Universidad de La Guajira, Riohacha, Colombia; iajimenez@uniguajira.edu.co, \\ gmolina@uniguajira.edu.co \\ ²Ambientales Agua, Aire y Suelo, Universidad de Pamplona, Colombia; jordipalaciosg@gmail.com,
}

\begin{abstract}
Objective: The objective of this research was the development of the ECAME software which analyzes the quality of estuarine and marine waters. Materials and Methods: The development of the software has its bases in the calculation and interpretation of mathematical modeling for parameters as: BOD, $\mathrm{pH}$, dissolved oxygen, thermotolerant coliforms, nitrates, phosphates, total suspended solids and chlorophyll $\alpha$. The software integrates a series of logarithms established by equations calibrated through a series of curves function based on a constant value previously established. Findings: The equations, weights and computational modeling were carried in the Java programming language, which presents a graphical interface to enter data generates a value that indicates the status of the water as: optimum, adequate, acceptable, inadequate and poor. In addition, describes the percentage of reliability of the analysis. It is concluded that the development of applications to determine the quality of the water is a step forward for the multidisciplinary research already integrates knowledge of mathematics, physical-water chemistry and computer science. Application/improvements: The water quality indexes (ICA) are represented by numerical values. These are interpreted by ranks, which give an overview of the status of water quality on a specific point using mathematical calculations. The indexes facilitate the handling of data; avoid fluctuations in measurements that alter the results of the environmental trends.
\end{abstract}

Keywords: Curves of Function, Development, Equations, Indicators of Water Quality Parameters

\section{Introduction}

Water is the substance essential to all aspects of life, it is necessary to ensure sufficient supply and quality appropriate to meet the demands of the present generation and future generations ${ }^{1}$. The estaurios, over time have been affected and altered in its natural cycles due to anthropogenic action. Therefore, it is necessary to establish measures of prevention and monitoring of our water sources for resources to be sustainable over time and space, these are done through analysis of physicochemical, biological and microbiological; with which determines the status of water quality to the group a cer- tain amount of parameters to obtain a result in a timely manner. The Water Quality Index (WQI) are represented by numerical values interpreted by ranks, which through mathematical calculations give an overview of the status of water quality at a specific point. The indexes facilitate the handling of data, because they prevent fluctuations in measurements alter environmental trends and cast information, which is interpreted in a simple and truthful? Therefore, useful or accessible to the political authorities and the general public. In addition, they can be used as reference to communicate information about the quality of the affected environment and to assess the vulnerability or susceptibility of water pollution ${ }^{3}$. 
Table 1. Descriptor Index, numeric ranges of ICAMPFF and indicator of water quality (4)

\begin{tabular}{|l|l|c|l|}
\hline $\mathbf{N}^{\circ}$ & Descriptor Index & Numeric ranges of ICAMPFF & Indicator of water quality \\
\hline 1 & Lousy & $0-25$ & Water with many restrictions that do not allow a proper use \\
\hline 2 & Inadequate & $25-50$ & Water that has many restrictions on use \\
\hline 3 & Acceptable & $50-71$ & Water that presents good conditions and few restrictions on use \\
\hline 4 & Adequate & $71-90$ & Water with good conditions for aquatic life \\
\hline 5 & Optimal & $91-100$ & Wáter quality excellent \\
\hline
\end{tabular}

The objective of this research was the development of the software to evaluate the quality of estuarine and marine waters (ECAME), which is Ueda used to make measurements in marine waters of parameters such as: Dissolved Oxygen, $\mathrm{pH}$, total suspended solids, biochemical oxygen demand, thermotolerant coliforms, dissolved and dispersed hydrocarbons, nitrates and phosphates. In addition, in estuarine waters Used: Dissolved Oxygen, $\mathrm{pH}$, total suspended solids, biochemical oxygen demand, chlorine, thermotolerant coliforms, Nitrates and Phosphates. These variables are represented according to their acceptance or rejection of the quality or condition based on values referenced by national or international standards and that the considered suitable to protect the habitat of a species or a community in ecosystems $s^{4,5}$.

To determine if the water is good or bad, it is first necessary to make reference to the fact that use is intended ${ }^{6}$. The tolerable limits of the various substances contained in the water are standardized by the World Health Organization (WHO), the Pan American Health Organization (PAHO), and by national governments, and may vary slightly from one to the other ${ }^{\mathrm{T}}$. The quality criteria eligible for the preservation of flora and fauna, in fresh water, cold or warm and estuarias in marine waters or in Colombia are regulated through Decree 1594 of the Ministry of the Environment, Housing and Territorial Development ${ }^{-}$. The water quality indicators are instruments of reference used for the evaluation of the physico-chemical and sanitary. As shown in Table 1 the indicator of environmental quality of estuarine and marine waters is represented by a set of physical, chemical and microbiological, who disclose their status to the study and relate it to the optimal conditions for the preservation of the flora and fauna ${ }^{6}$.

\section{Materials and Methods}

The approach includes a scale of five levels of quality defined between 0 and 100 as can be seen in Table 1, which manages to summarize the information of the variables considered in the study (dissolved oxygen-OD, $\mathrm{pH}$, nitrates- $\mathrm{NO}_{3}$, phosphates- $\mathrm{PO}_{4}$, suspended solids SST, dissolved and dispersed -HAT, and thermotolerant coliforms - CTE). These variables are integrated by weights as described the equation 1 marine and estuarine waters, and in the equation 2 indicates that the ICAM is a weighted geometric mean $\frac{4,9,5}{}$.

$$
\mathrm{ICAM}=\left(\prod_{i=1}^{n} X_{i}^{w i}\right) 1 / \sum i w i
$$

Equation 1

where:

ICAM $=$ water quality index.

$\mathrm{Xi}=$ sub Index of quality of water quality.

$\mathrm{Wi}=\mathrm{a}$ weighting factor for each sub index $\mathrm{i}$ according to their importance.

$$
\begin{aligned}
\mathrm{ICAM}= & {\left[\left(\mathrm{X}_{\mathrm{OD}}\right)^{0.12 *}\left(\mathrm{X}_{\mathrm{pH}}\right)^{0.12 *}\left(\mathrm{X}_{\mathrm{SST}}\right)^{0.13 *}\left(\mathrm{X}_{\mathrm{DBO}}\right)^{0.13 *}\left(\mathrm{X}_{\mathrm{CTE}}\right)^{0.14 *}\right.} \\
& \left.\left(\mathrm{X}_{\mathrm{HAT}}\right)^{0.12 *}\left(\mathrm{X}_{\mathrm{NO} 3}\right)^{0.09 *}\left(\mathrm{X}_{\mathrm{PO} 4}\right)^{0.12}\right] \quad \text { Equation 2 }
\end{aligned}
$$

In Table 2 we can see the weighting factor (i) in each one of the variables (Sub i) that were used for the estimation of the level of quality of marine waters, with its respective weight $(\mathrm{Wi})^{\underline{5}}$.

Table 2. Sub i and weight of the weighting factors (i) for marine waters

\begin{tabular}{|c|c|c|}
\hline $\mathbf{N}^{\circ}$ & Sub $\mathbf{i}$ & $\mathbf{W i}$ \\
\hline 1 & OD & 0.12 \\
\hline 2 & ${ }_{\mathrm{P}} \mathrm{H}$ & 0.12 \\
\hline 3 & SST & 0.13 \\
\hline 4 & DBO & 0.13 \\
\hline 5 & CTE & 0.14 \\
\hline 6 & HAT & 0.12 \\
\hline 7 & $\mathrm{NO}_{3}$ & 0.09 \\
\hline 8 & $\mathrm{PO}$ & 0.13 \\
\hline
\end{tabular}

In Table 3 we can see the weighting factor (i) in each one of the variables (Sub i) that were used for the estimation of the level of quality of estuarine waters, with weight (Wi). 
Table 3. Sub i and weight of the weighting factors (i) for estuarine waters

\begin{tabular}{|c|c|c|}
\hline $\mathbf{N}^{\circ}$ & Sub i & Wi \\
\hline 1 & OD & 0.16 \\
\hline 2 & ${ }_{\mathrm{P}} \mathrm{H}$ & 0.11 \\
\hline 3 & SST & 0.13 \\
\hline 4 & DBO & 0.13 \\
\hline 5 & CTE & 0.14 \\
\hline 6 & HAT & 0.12 \\
\hline 7 & $\mathrm{NO}_{3}$ & 0.09 \\
\hline 8 & $\mathrm{PO}_{4}$ & 0.12 \\
\hline
\end{tabular}

Figures 1 shows the curves of feature set for each of the parameters: In Figure 1A you can see the curve as a function of $\mathrm{pH}$ which measures the acidity, this parameter is set to a range of 0 to 14 , and the average value (range 7 is neutral). If the value of the $\mathrm{pH}$ is less than 7 , this indicates that we are in the presence of some acid waters, if it is greater than 7 indicates that are basic ${ }^{4,5}$. In Figure $1 \mathrm{~B}$ you can see the function curve of the dissolved oxygen (DO), this indicator refers to the amount of oxygen that is dissolved in the water. This in turn depends on the temperature of the water; the higher the temperature, the less oxygen dissolves. The higher the amount of dissolved oxygen will have a lesser degree of contamination $\stackrel{4.9}{ }$.

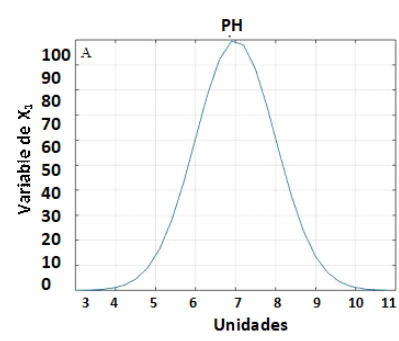

(A)

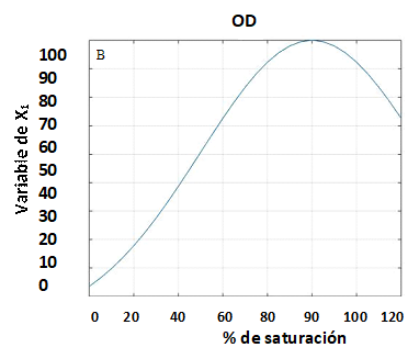

(B)
Figure 1. Curves as a function of $\mathrm{pH}$ and (B) the dissolved oxygen

Figure 2A shows the function of the Biochemical Oxygen Demand (BOD), which determines the amount of organic matter and amount of oxygen needed for the degrade ${ }^{4,9}$. Figure $2 \mathrm{~B}$ describes the curve as a function of the thermotolerant coliforms (CTE), which in the water is proportional to the degree of faecal contamination; while more coliforms are isolated from the water, the greater the severity of the discharge of feces $\$$.,9.

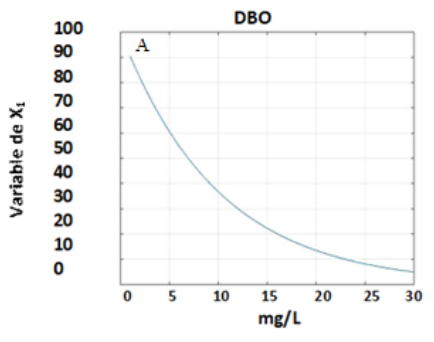

(A)

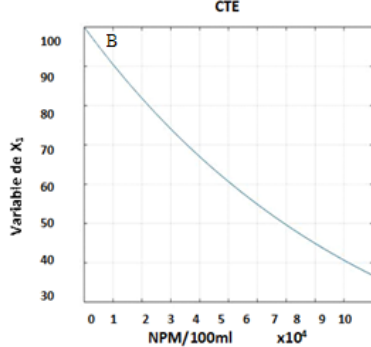

(B)
Figure 2. (A) Function curve of the biochemical oxygen demand and (B) thermotolerant coliforms.

Figure $3 \mathrm{~A}$ shows the function curve of the nitrates, which are composed of nitrogen and oxygen, a high presence of nitrate in water indicates high water pollution 19.9 . Figure 3B describes the function curve of the phosphates, which are composed of phosphorus and oxygen, these are necessary for life, but the excesses of phosphates cause an excessive growth of algae and eutrophication (accumulation of organic waste) of water sources ${ }^{4,9}$. In the same way the function curves for other variables. For each was established an equation based on the value of the weight of these parameters for either marine or estuarine waters, as described in Tables 1, 2.

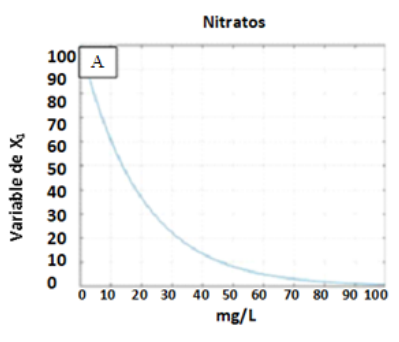

(A)

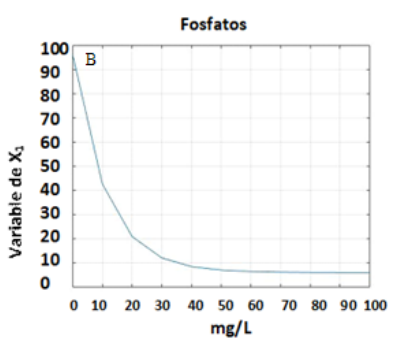

(B)
Figure 3. (A)Function curve of nitrates and (B) phosphate

\section{Results and Discussion}

The model of the equation of ICAM, with the following code in the equation 3 :

$$
\begin{aligned}
& \mathrm{ICAM}=\left[(\mathrm{X} 1 \mathrm{~W} 1)^{*}(\mathrm{X} 2 \mathrm{~W} 2)^{*}(\mathrm{X} 3 \mathrm{~W} 3)^{*}(\mathrm{X} 4 \mathrm{~W} 4)^{*}(\mathrm{X} 5 \mathrm{~W} 5)^{*}\right. \\
& \left.(\mathrm{X} 7 \mathrm{~W} 7)^{*}(\mathrm{X} 8 \mathrm{~W} 8)\right](1 / \text { wi); } \quad \text { Equation } 3 \\
& \mathrm{ICAM}=\operatorname{abs}(\mathrm{ICAM}) \\
& \text { Code for the weights: } \\
& \mathrm{w} 1=0.16 ; \mathrm{w} 2=0.12 ; \mathrm{w} 3=0.12 ; \mathrm{w} 4=0.13 ; \mathrm{w} 5=0.14 \text {; } \\
& \mathrm{w} 6=0.12 ; \mathrm{w} 7=0.09 ; \mathrm{w} 8=0.12 ; \mathrm{wi}=0 \text {; }
\end{aligned}
$$




$$
\begin{aligned}
& \text { if } \mathrm{X} 11=1 \text {; wi = w1; End } \\
& \text { if } \mathrm{X} 2=1 \text {; } w i=w i+w 2 \text {; End } \\
& \text { if } \mathrm{X} 3=1 \text {; wi = wi + w3; End } \\
& \text { if } \mathrm{X} 4=1 \text {; } w i=w i+w 4 \text {; End } \\
& \text { if } \mathrm{X} 5=1 \text {; wi }=w i+w 5 \text {;End } \\
& \text { if } X 6=1 \text {; wi }=w i+w 6 \text {;End } \\
& \text { if } X 7=1 ; w i=w i+w 7 \text {; End } \\
& \text { if } \mathrm{X} 8=1 \text {; wi = wi + w8; End }
\end{aligned}
$$

Taking the equation of ICAM and the curves of the function is raised the algorithmic model that calculates the water quality indexes, this design a user-friendly graphical interface and ease of use, as can be seen in Figure 4.

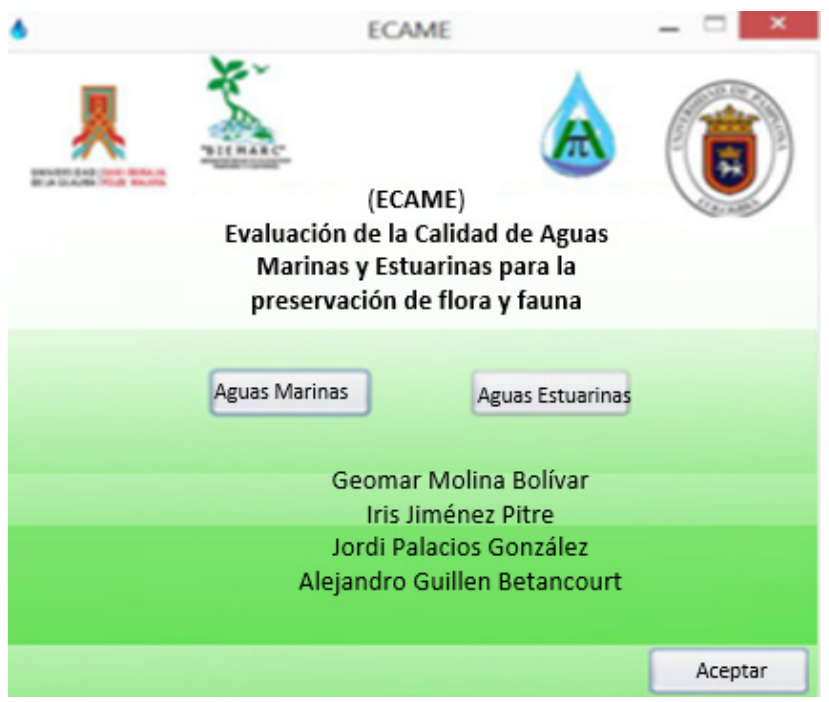

Figure 4. Menu of the graphical interface of the software ECAME.

Subsequently created two graphical interfaces in which you can see the names of the parameters, units and range of values; where the user can enter the data manually for each parameter. In these interfaces the user the software solves the system of equations by calculating the water quality in numbers (0-100) and ranges (Lousy, inadequate, acceptable, appropriate, and optimal). An interface is for the sea water as you can see in Figure 5, and the other for estuarine water (Figure 6); the estuarine waters have a salt content that varies between 5 to 100 ppm of sodium chloride, while the marine waters are characterized by having a salt content of relatively stable that ranges from 34 to 35 ppm. Weightings vary for the two types of water and the range of values of the curves of function.

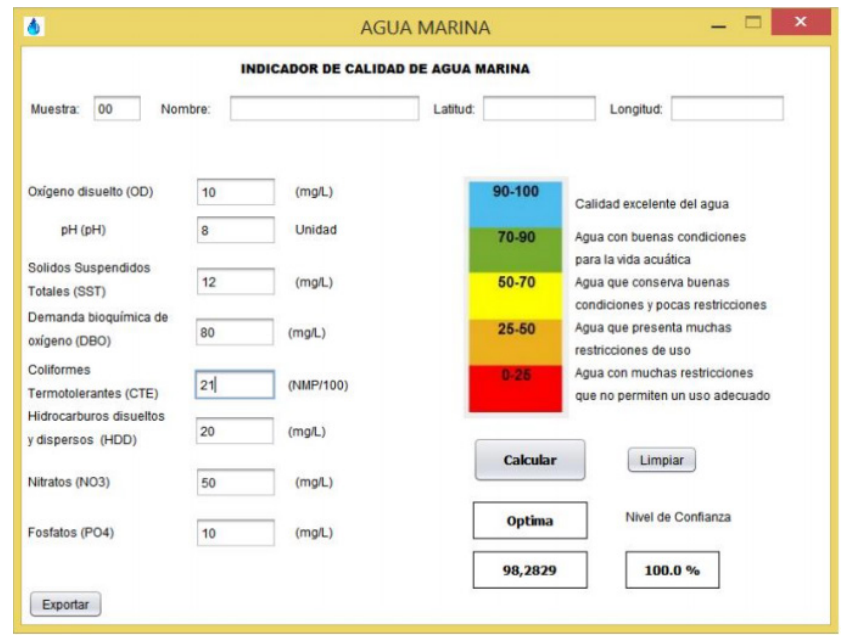

Figure 5. Interface to the indicators of the quality of the marine waters.

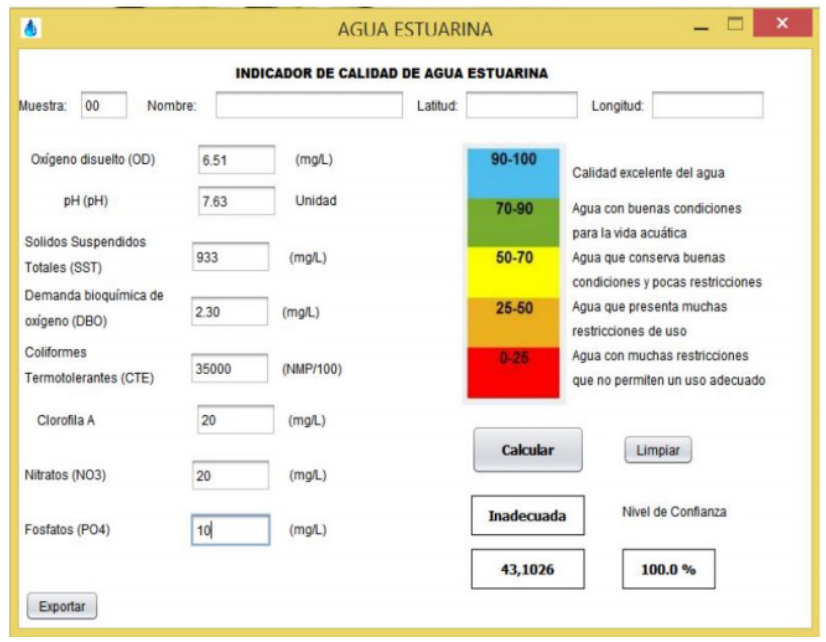

Figure 6. Interface to the indicators of the quality of estuarine waters.

Each parameter was calibrated individually from the other in order to ensure the reliability of the results to match the ranges set. In addition, account was taken of the amount of data supplied to compute the confidence level in percentage (between more data is inserted into the application, the greater the level of trust, these are taken into account by the sum of the weights of the parameters). The development of the ICA has played a very important role in the environmental and ecological context, their weaknesses constitute a major obstacle to their application, as to concentrate on a single number the quality of a body of water, there is an immense loss of information $\frac{5,6,10}{5}$. 


\section{Conclusions}

Water quality assessment is a breakthrough in the multidisciplinary research due to the fact that integrates the knowledge of water chemistry, mathematics and computer science, mainly this type of software as a point of comparison to determine water quality in different places. The results obtained by the software are approximate, due to the water conditions are variable and to study the interaction between parameters is different for each areas that is applied, this is taken as an idealized system and subject only to the variables determined. The software was developed in MatLab to generate a file.exe; the consulted documentation in the official site of Matlab says that the.exe is executed without problems in the Windows operating systems 7, 8 and 10. Unfortunately, the practice is contrary to the above, due to the fact that the software developed did not work on other computers different to that development. To solve the problems of implementation, the best option was to migrate to the Java programming language.

\section{References}

1. Troyer W, Brundtland G. Preserving our world: A consumer's guide to the brundtland report. 2nd Edition. Firefly Books Ltd; 1990.

2. Alberti M, Parker J. Indices of environmental quality, the search for credible measure. Environmental Impact Assessment Review. 1991; 11(2):95-101. Crossref.
3. Canter L. Manual de evaluación del impacto ambiental. Técnicas para la elaboración de estudios de impacto. Primera Edition. McGraw Hill; 1998.

4. Vivas-Aguas LJ, Navarrete-Ramírez SM. Protocolo Indicador Calidad de Agua (ICAMPFF). Indicadores de monitoreo biológico del Subsistema de Áreas Marinas Protegidas (SAMP). Santa Marta: Invemar, GEF y PNUD; 2014.

5. Vivas-Aguas LJ. Formulación del índice de calidad de aguas costeras para los países del Proyecto Spincam: Documento Metodológico. Red de información y datos del Pací!co Sur para el apoyo a la gestión integrada del área costera (SPINCAM). Santa Marta: Invemar-Programa Calidad; 2011.

6. Severiche C. Efecto de las lluvias sobre la calidad del agua en la ciénaga grande de santa marta, caribe Colombiano en periodo 2006-2009. Universidad de Manizales Maestría en Desarrollo Sostenible y Medio Ambiente Manizales; 2013. p. $1-70$.

7. Smith D. A better water quality indexing system for rivers and stream. Water Research. 1990; 24(10):12-37. Crossref.

8. Ministerio de Ambiente, Vivienda y Desarrollo Territorial [MAVDT]. Ploítica Nacional para la gestión integral del recurso hídrico Bogotá: Ministerio de Ambiente, Vivienda y Desarrollo Territorial (MAVDT); 2010. p. 1-124.

9. Vivas-Aguas L, Espinosa LF, Henríquez L. Identificación de fuentes terrestres de contaminación y cálculo de las cargas de contaminantes en el área de influencia de la Ciénaga Grande de Santa Marta, Caribe Colombiano. Boletín de Investigaciones Marinas y Costeras. 2013; 42(1):7-30.

10. Samboni N, Carvajal Y, Escobar J. Revisión de parámetros fisicoquímicos como indicadores de calidad y contaminación del agua. Ingeniería e Investigación. 2007; 27(3):172-81.v 